\title{
Assessment of WWTP design and upgrade options: balancing costs and risks of standards' exceedance
}

\author{
L. Benedetti ${ }^{1 *}$, D. Bixio ${ }^{2}$, and P.A. Vanrolleghem ${ }^{1}$ \\ ${ }^{1}$ BIOMATH, Ghent University, Coupure Links 653, B-9000 Ghent, Belgium \\ 2 Aquafin nv, Technology Department, Dijkstraat 8, B-2630 Aartselaar, Belgium \\ *Corresponding author, e-mail lorenzo.benedetti@biomath.ugent.be
}

\begin{abstract}
Numerical models can be used to evaluate design and upgrade scenarios of urban wastewater systems on the basis of their ecological consequences. The objective of this paper is to illustrate a systematic procedure of system design/upgrade. This procedure consists of the following steps: 1) data collection and data reconstruction, 2) model building and calibration, 3) evaluation of scenarios, 4) uncertainty assessment. In contrast to conventional practice, this approach allows to choose the most appropriate trade-off between cost of measures and risk of non-compliance with regulatory limits. An example of its application dealing with the assessment of WWTP design and upgrade options is provided. Results show that by reducing the tank volumes compared to conventional design procedures, costs can be reduced sensibly while the risk of not meeting legislative requirements are only slightly increased.
\end{abstract}

\section{KEYWORDS}

Cost-effectiveness, mathematical modelling, Monte Carlo simulation, risk-based design, urban wastewater systems

\section{INTRODUCTION}

The European Water Framework Directive (WFD) requests to achieve good quality for ground and surface waters by organising water management on a river-basin scale and - with regard to impacts on natural water bodies originating from wastewater release - applying a combined emission and water quality based approach. There is therefore a need to evaluate and quantify what potential costs and benefits could result from the WFD approach, which is setting water quality goals in the natural water bodies instead of prescribing the design of urban wastewater systems. With this new water quality based approach, the design of the systems is by far less predetermined and the options to meet the goals become much more numerous. Therefore new design methodologies must be developed in order to be able to cope with such increased complexity. The EU project CD4WC (www.cd4wc.org) is currently tackling these problems, focussing on the urban wastewater system.

This paper outlines a new methodology to identify and quantify the costs and benefits for the development of the urban wastewater system resulting from the WFD approach, with regard to its ecological and economic consequences. Criteria to assess the ecological consequences are - besides the water quality - also secondary resource inputs such as energy, materials and chemicals.

The developed methodology is illustrated in this paper by a case of WWTP design, with comparisons between three process options and between different activated sludge tanks volume for one process option. Traditionally, treatment plants have been designed using empirical steady-state equations or "rules of thumb", introducing conservative safety factors. 
Such approach has led to the construction of overdimensioned, expensive, and not always properly functioning plants. To design or upgrade a treatment plant, deterministic models can be used, since their parameters have a straightforward physical meaning and can be directly measured in the system or applied to it (in case of obtained volumes, recycle rates, etc.).

The software tool used in this study is able to deal with complex models including draining catchment, sewer system, WWTP and receiving water (Benedetti et al. 2004; Solvi et al. 2005; Vanrolleghem et al. 2005).

\section{METHODS}

The methodology consists of four steps: (1) data collection and reconstruction, (2) model building and calibration, (3) evaluation of alternatives and (4) uncertainty assessment.

\section{(1) Data collection and reconstruction}

Data collection is probably the most challenging task. In order to evaluate upgrade alternatives, long term (several representative years) dynamic influent data are advisable. In absence of these data, influent data can be reconstructed using available measurements and making assumptions on the influent properties (e.g.(Bixio et al. 2002)). In the proposed procedure, a dynamic influent is generated using a simple model of the draining catchment (Gernaey et al. 2005), which considers the number of inhabitants, the presence of industry, the loads per capita of households and industry, the size of the catchment, the length of the sewer system, rainfall data, and the interactions with groundwater.

\section{(2) Model building and calibration}

The most used models for biological treatment are the IWA activated sludge models (ASM) (Henze et al. 2000). Other important parts of the plant that need to be modelled are secondary settlers, aeration systems and anaerobic digesters when present.

In the case of a renovation or upgrade, relevant information to build and calibrate these models is often available. For such situations calibration methodologies can be found in a large number of publications, e.g. among the most comprehensive (Hulsbeek et al. 2002; Langergraber et al. 2003; Melcer et al. 2003; Vanrolleghem et al. 2003). This calibration should be performed by experienced modellers to limit the possibility of misinterpretation of the model results. After having obtained a calibrated model of the plant, several upgrade options can be implemented by modifying and/or extending the plant model configuration, by increasing or adding volumes, modifying flow paths, adding or changing processes, etc.

In the case of a design (i.e. no infrastructure is in place yet), standard parameter values should be applied for the used models, while operational variables are decided by the modeller, and optimal values for them will be identified by performing several simulations with different values, or applying an optimisation algorithm. In this case there is no calibration of the model to be performed, but only some adjustments to parameter values; e.g. if for any reason (temperature, influent characteristics, etc.) the expected Sludge Volume Index is higher than average, some parameters in the secondary settling model should be modified.

\section{(3) Evaluation of scenarios}

The comparison of alternative scenarios can be based on performance criteria that can be grouped into two categories: environmental and economic criteria. The weight attributed to them in the decision making process depends to the specific situation of the project. 
Environmental performance. The proposed methodology adopts the approach set out by IWA (Copp et al. 2002). It consists of the evaluation of three indicators: the effluent quality index, the time and number of effluent violations, and operating costs.

The effluent quality index (EQI) is meant to quantify the effluent pollution load to a receiving water body in a single variable. The EQI is the weighted sum of the pollution loads due to (1) total suspended solids (TSS), (2) chemical oxygen demand (COD), (3) biological oxygen demand after 5 days (BOD5), (4) total Kjeldahl nitrogen (TKN), (5) nitrates and (6) total phosphorus (TP) over one complete year. The used weights are based on (Vanrolleghem et al. 1996) that cited a Flanders' effluent quality formula for calculating fees. Note that the formula is not based on actual environmental damage but on operating cost to treat the pollutants.

Effluent violations are calculated for five terms: ammonia, total nitrogen (TN), BOD5, COD and TSS. The number of violations as well as the percentage of time that the constraints are not met is calculated from the output data generated at 15-minute intervals.

Operational issues are considered through four items: sludge production, pumping energy, aeration energy and mixing energy. Sludge production is accounted as mass of TSS to be disposed, while energy is in kWh consumed.

Economic performance. The evaluation of costs for wastewater treatment is very complex. In a European context, costs can differ among countries or regions because of different specific conditions and also because of differences in planning and building procedures (Bode and Lemmel 2001). This complexity makes the approach to calculate costs in order to compare different plant configurations and operational strategies very difficult. Detailed cost calculations should in general be preferred over the use of cost functions, which can only be useful for rough estimations. Most WWTPs are tailored to specific conditions/needs, i.e. plants with the same treatment performances do not inevitably incur into the same costs. The use of cost functions is feasible only for process options screening (Gillot et al. 1999), i.e. as it is the case here. In this project, operating costs have been estimated with the benchmark assessment procedure (Copp et al. 2002) and with prices representative for northern Europe, while the capital costs were provided by Ruhrverband (Germany).

\section{(4) Uncertainty assessment}

It is an increasingly common practice to use deterministic dynamic models to evaluate design and renovation scenarios of WWTPs. One of the remaining issues when dealing with these deterministic models is the degree of uncertainty linked to their predictions.

Probabilistic design, which is the combination of probabilistic modelling techniques with the currently available deterministic models, provides a solution to this issue (Bixio et al. 2002). By building a probabilistic shell around the deterministic models one can quantify the uncertainty of the model predictions. For example, a goal can be to determine the probability of exceeding the legal effluent standards of a WWTP. This percentage of exceedance should be accompanied by confidence intervals indicating the uncertainty due to the variability of influent characteristics and to the uncertainty in model parameters.

The quantification of the uncertainty of the system as a whole may be carried out by the following steps (Rousseau et al. 2001): (1) assigning information about the probability distribution of each parameter and input variable in the system; (2) for every simulation with the deterministic value, the simulator uses a value for each parameter and input variable (a "shot") that is randomly selected by a Monte Carlo engine from the appropriate probability density function. Over multiple simulations, the Monte Carlo engine produces a range of values for the parameters and input variables that cover the probability density function; (3) the deterministic model is solved for each shot, as it would be for any deterministic analysis; all these simulations are independent from each other, and can thus be run in parallel. 
This iterative process generates a probability density function or cumulative density function of the output. Based on the distribution of the output, a risk level representing the high end (e.g. $95^{\text {th }}$ percentile), central tendency (median or mean), or any other desired level of probability can be identified. See Figure 1 for two examples of uncertainty visualisation.
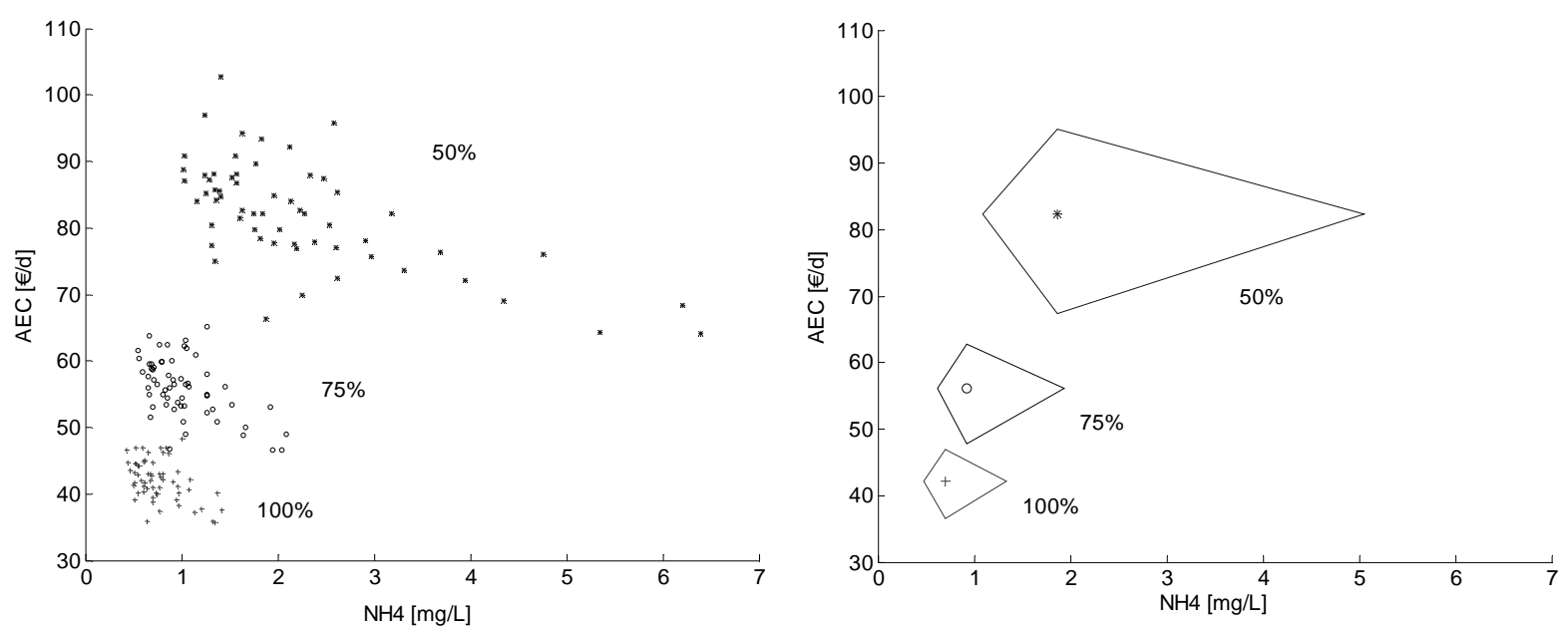

Figure 1. Two options to visualise Monte Carlo simulation results: all results as a cloud of markers (left) and polygons joining the $5^{\text {th }}$ and $95^{\text {th }}$ percentiles for the two variables and the $50^{\text {th }}$ percentile as a marker (right); the data show effluent $\mathrm{NH}_{4}$ and aeration costs for different tank volumes (as percentage of conventional dimensioning volume).

The number of necessary simulations for scenario analysis tends to be large, especially when Monte Carlo-based uncertainty assessment is also considered. Hence, a major limitation for a more widespread use of probabilistic design techniques is the calculation time required. To reduce this computational burden, tools that distribute simulations over idling PCs available in a local network are under development (Claeys et al. 2004).

\section{RESULTS AND DISCUSSION}

The procedure is illustrated for the case of WWTP design, either for the comparison between process options or between different activated sludge tank volumes for one process option.

The chosen catchment characteristics (generating the wastewater to be treated) refer to a combined sewer system collecting 30.000PE (of which 15\% of COD load as industry), located in an area with Oceanic climate conditions (characterized by an actual rainfall series for a representative year with 10 minutes interval, and a daily temperature series), with infiltration as $30 \%$ of dry weather flow, having a weekend loads increase of $12 \%$ and a summer loads decrease of 25\%. All loads are taken from (ATV 2000). The TN load is increased with $10 \%$ above the ATV load to consider the presence of reject water from the sludge treatment line. The influent time series was generated with the model of (Gernaey et al. 2005)). The used rainfall series and an example of WWTP influent are shown in Figure 2. Three process configurations are compared: low loaded activated sludge (LLAS), LLAS with primary settler (PS) and oxidation ditch (OD), all equipped with simultaneous chemical phosphorus precipitation. Such processes have been dimensioned according to the guidelines contained in (ATV 2000), in order to represent existing treatment plants, and modelled using ASM2d (Henze et al. 2000).

In this work the number of parameters considered as uncertain was 13 (11 belonging to ASM2d and 2 to the influent fractionator model), and for each configuration 60 Monte Carlo simulations were run; this number was sufficient to reach the convergence of the output 
frequency distributions. The natural variability of the influent is assumed to be represented in the one year time series with 15 minutes intervals.
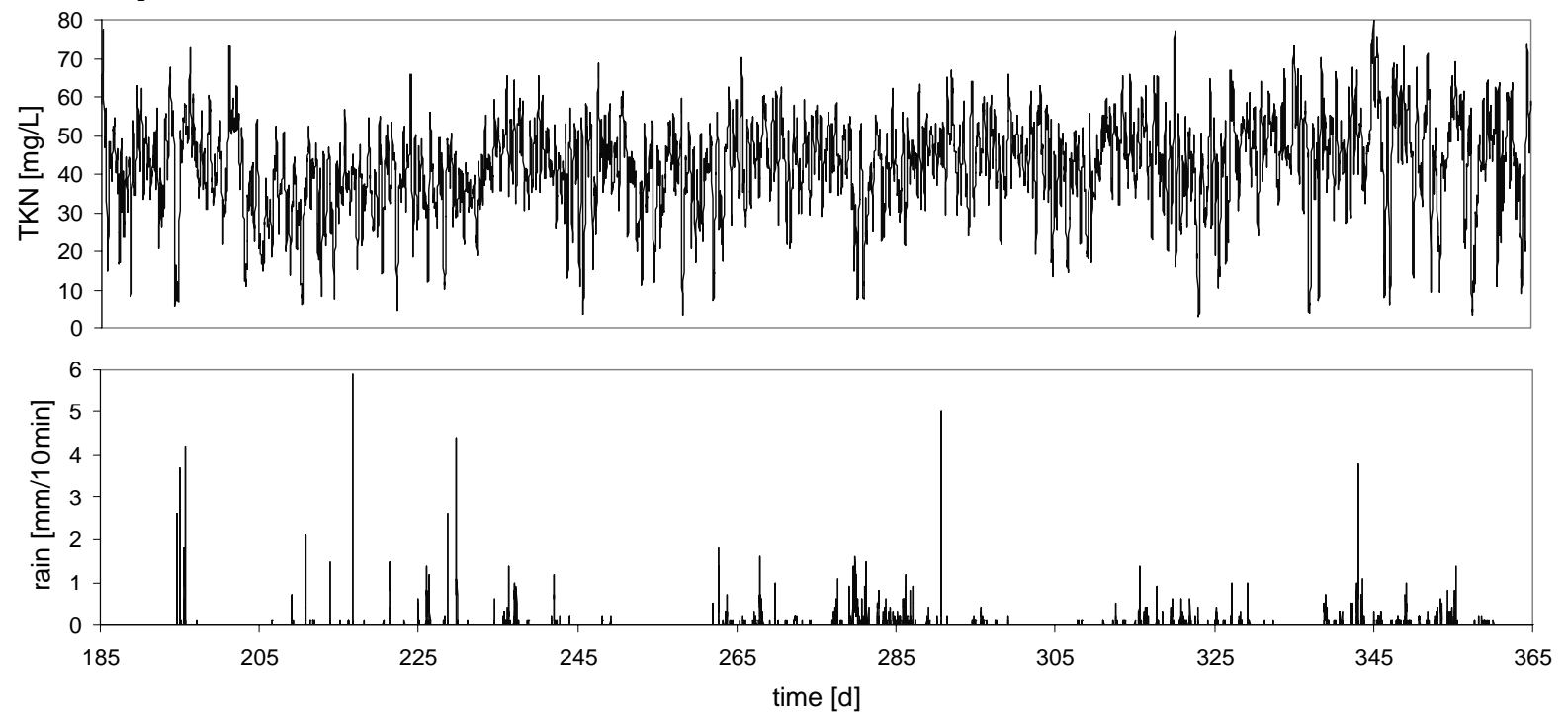

Figure 2. Rainfall for Oceanic climate (down) and TKN influent of the 30.000PE plant (up).

\section{Comparison of different process alternatives}

The performance of the three simulated processes is summarised by the EQI and by the total cost (sum of aeration, pumping, mixing, chemicals, sludge treatment and disposal and annualised capital costs). In Figure 3 such indices for the three processes are shown for the dimensioning according to the ATV guidelines (left) and for a volume reduction to $70 \%$ of the biological treatment tanks (right).
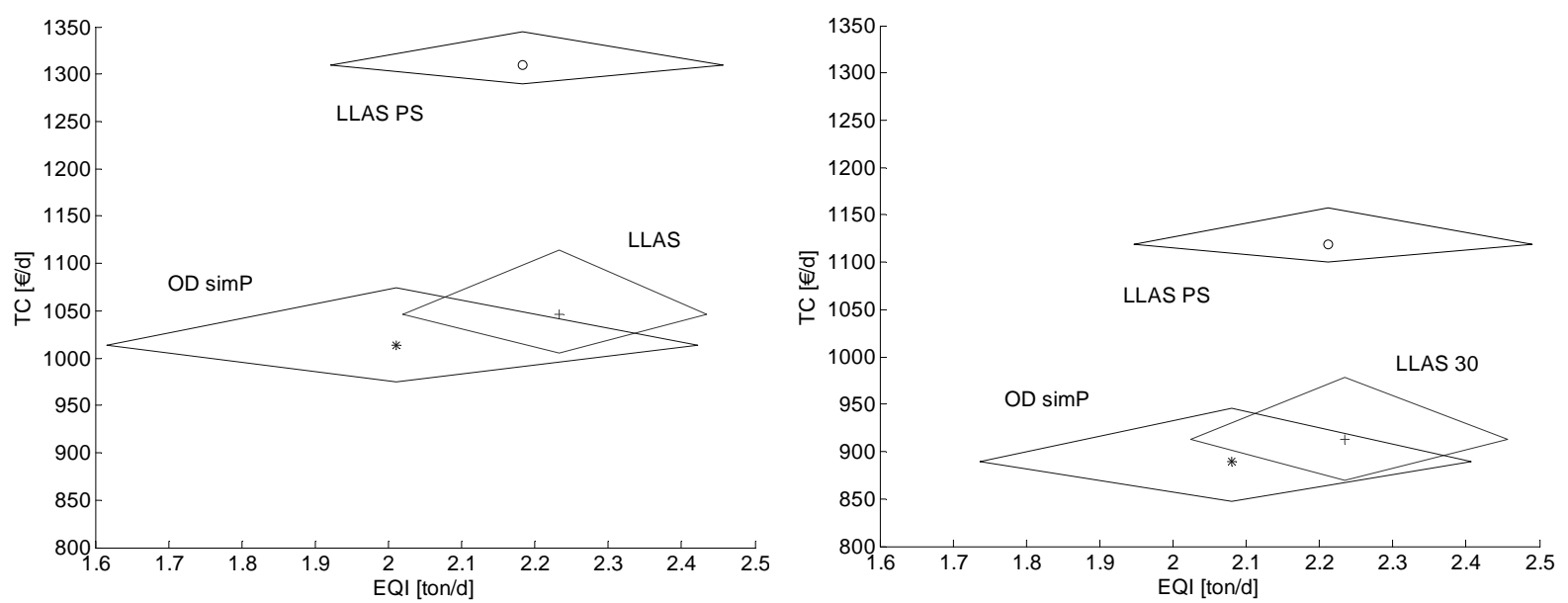

Figure 3. Comparison of three alternatives: volumes from ATV guidelines (left) and $70 \%$ of biological tanks volume (right).

From Figure 3 several conclusions can be drawn. First of all, apparently LLAS with PS is not a suitable configuration in this situation, since it shows higher costs without giving additional removal performance; note that this conclusion no longer holds in case anaerobic digestion is also present, to which primary sludge is of great benefit. The OD performs slightly better then LLAS both in economic and environmental terms, but it shows a larger uncertainty in its behaviour, and this is probably due to the fact that in the used model configurations only very basic control features were implemented (dissolved oxygen set-point for all of them, with fixed aerated phase length for the OD), while the OD process performs more stably with additional control systems (e.g. variable aerated phase length based on $\mathrm{NH}_{4}$ measurements). 
Furthermore, a reduction of volumes seems to be more beneficial to a reduction of costs than it is detrimental to the removal of pollutants.

\section{Comparison of different tank volumes}

The LLAS process was further investigated by simulating it with several activated sludge tank volumes, ranging from $100 \%$ to $50 \%$ of the volume calculated with the ATV guidelines, with $5 \%$ intervals for a total of 11 models to simulate. In Figure 4 two comparisons are presented. It can be deduced that the removal of pollutants only deteriorates significantly from a volume smaller than $60 \%$ of the original one. Of course the total costs are constantly reduced. In particular, with smaller volumes the TP removal improves, leading also to a reduction of chemical dosage. Figure 1 shows that, on the other hand, smaller volumes produce higher ammonia effluents and require higher aeration costs.
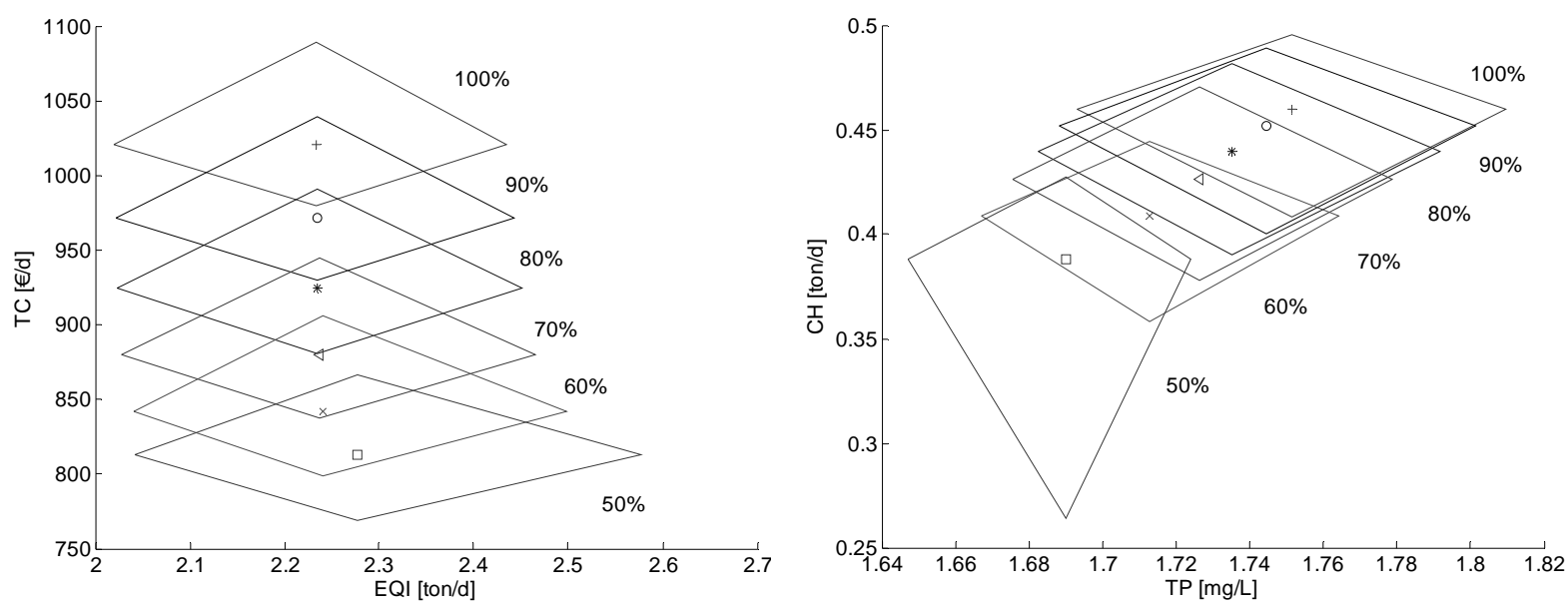

Figure 4. Comparison of different volumes for LLAS: EQI and total cost (left), TP and Pprecipitant dosage (right).

Another use of the proposed methodology can be the comparison of concentration-exceedance curves, as illustrated in Figure 5 and Table 1. Figure 5 compares the concentrationexceedance curves calculated with 24-hour (left) and 2-hour (right) averages of TN concentrations for the LLAS plant with $70 \%$ of the "ATV volume". It shows that less effluent variability is revealed with 24-hour averages (curves are more vertical), which leads in this case to a conservative estimate of the risk of exceedance of e.g. a limit of $15 \mathrm{mgTN} / \mathrm{L}$, compared to the use of 2-hour composite samples as referred to e.g. in the German legislation.
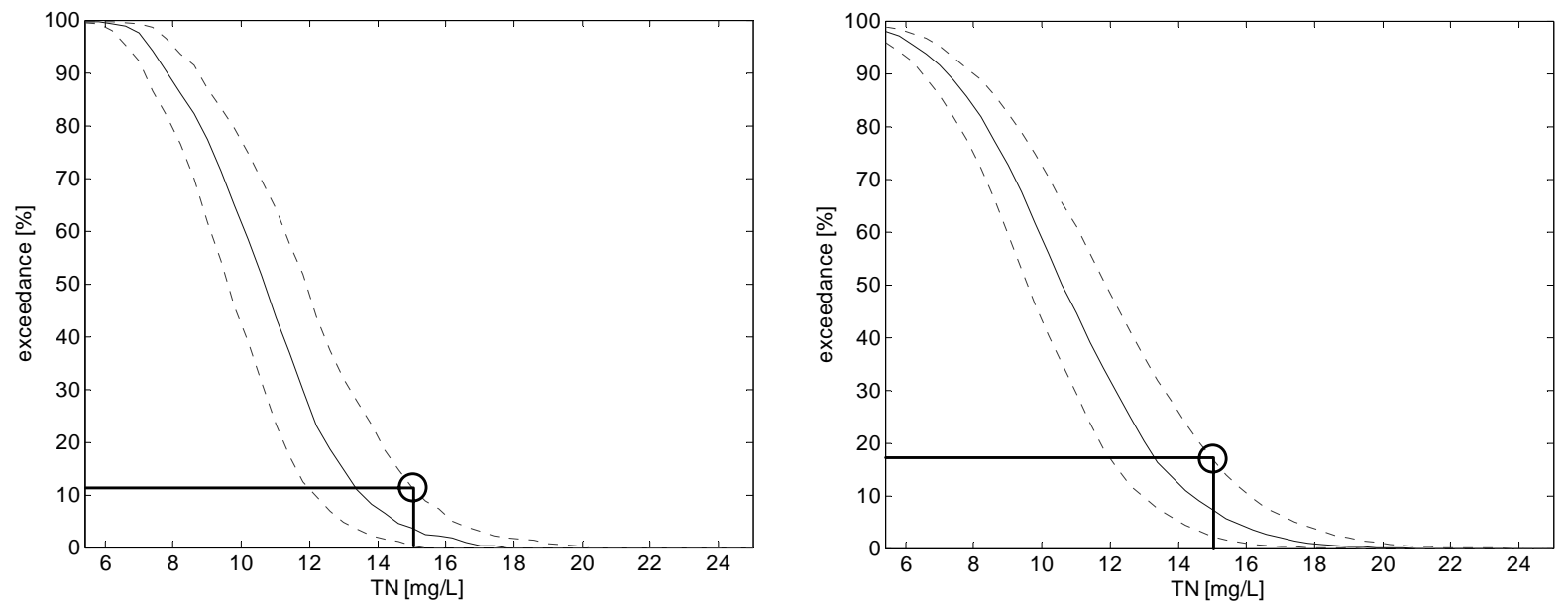

Figure 5. Comparison of TN concentration-exceedance curves for LLAS with 75\% of "ATV volume": 24-hour (left) and 2-hour (right) averages; full line: $50^{\text {th }}$ percentile, dotted lines: $5^{\text {th }}$ and $95^{\text {th }}$ percentiles. 
This is more evident in Table 1, where for the same plant the risk of exceedance of $15 \mathrm{mgTN} / \mathrm{L}$ is given as $5^{\text {th }}, 50^{\text {th }}$ and $95^{\text {th }}$ percentiles; direct evaluation of the original 15minute interval data (which can be considered as data coming from an on-line monitoring system) is also included. It can therefore be argued that a risk-based dimensioning is dependent on the local legislation, which can require different criteria to be fulfilled (yearly average, 2-hour average percentiles, daily maxima, etc.).

Table 1. Exceedance risk as \% of time of $15 \mathrm{mgTN} / \mathrm{L}$ for LLAS with $75 \%$ of "ATV volume".

\begin{tabular}{|l|c|c|c|}
\hline & $5^{\text {th }}$ percentile & $50^{\text {th }}$ percentile & $95^{\text {th }}$ percentile \\
\hline 15-minute data & 2.3 & 7.4 & 17.0 \\
\hline 2-hour average & 2.2 & 7.3 & 16.9 \\
\hline 24-hour average & 0.4 & 3.7 & 11.4 \\
\hline
\end{tabular}

To resume the economic evaluation, the surfaces in Figure 6 represent, for different daily costs and different $\mathrm{NH}_{4}$ concentrations, the $95^{\text {th }}$ percentile of the exceedance period (as percentage of the total period of one year). For example, it can be deduced that with the "ATV volume" (corresponding to an operating cost of $380 € / \mathrm{d}$ ), one can be $95 \%$ sure that the $\mathrm{NH}_{4}$ concentration will not exceed $2 \mathrm{mg} / \mathrm{L}$ for more than $18 \%$ of the time, while with an operating cost of $500 € / \mathrm{d}$ (corresponding to $50 \%$ of the "ATV volume"), one can be $95 \%$ sure that $\mathrm{NH}_{4}$ concentration will not exceed $2 \mathrm{mg} / \mathrm{L}$ for more than $73 \%$ of the time. Hence, smaller volumes lead to substantially lower total costs, although the small disadvantages of increased $\mathrm{NH}_{4}$ emission and lower process stability have to be taken into account.
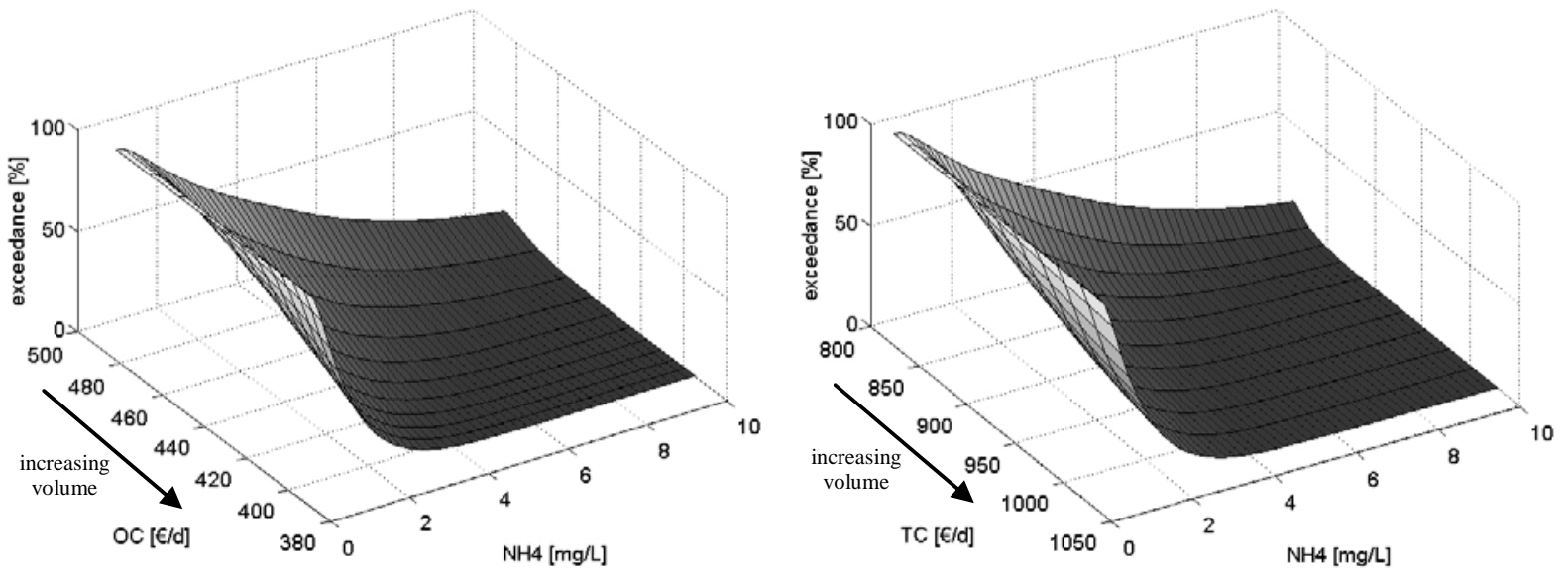

Figure 6. Comparison of different volumes for LLAS: \% of time with $\mathrm{NH}_{4}$ emission exceedance $\left(95^{\text {th }}\right.$ percentile) confronted with operational costs (left) and with total costs (right) and exceedance period as percentage of the total period.

\section{CONCLUSIONS}

A methodology for the assessment of urban wastewater systems has been outlined. The particular case of a WWTP design served as an example to illustrate the procedure. The capabilities of the software tools used allow to investigate the cost-effectiveness of measures for WFD compliance by using a dynamic integrated model including draining catchment, sewer system, treatment plant and receiving water. As for the WWTP dimensioning analysis, it can be concluded that building activated sludge volumes smaller than the ones traditionally calculated by applying design guidelines leads to considerable total cost reductions, while it entails only a small increase in the risk of not complying with emission standards. The same considerations can be applied to cases of plant upgrade, where the increase of risk can be 
evaluated for changes in the plant loading. The actual availability of well-accepted models, risk assessment techniques and sufficient computational power should move the design practice from the use of conservative and expensive rules to more advanced and cost-effective procedures.

\section{ACKNOWLEDGEMENT}

The results presented in this publication have been elaborated in the frame of the EU projects CD4WC, contract no EVK1-CT-2002-00118 and Harmoni-CA, contract no EVK1-CT-200220003.

\section{REFERENCES}

ATV (2000). Standard ATV-DVWK-A 131E. Dimensioning of Single-Stage Activated Sludge Plants.

Benedetti, L., Meirlaen, J., Sforzi, F., Facchi, A., Gandolfi, C. and Vanrolleghem, P. A. (2004). Dynamic integrated modelling: A case study on the river Lambro. In: Proceedings of NOVATECH 2004, Lyon, France, 6-10 June 2004.

Bixio, D., Parmentier, G., Rousseau, D., Verdonck, F., Meirlaen, J., Vanrolleghem, P. A. and Thoeye, C. (2002). A quantitative risk analysis tool for design/simulation of wastewater treatment plants. Water Science and Technology 46 (4-5), 301-307.

Bode, H. and Lemmel, P. (2001). International product cost comparison in the field of water management. Water Science and Technology 44 (2-3), 85-93.

Claeys, F., Chtepen, M., Benedetti, L., Dhoedt, B. and Vanrolleghem, P. A. (2004). Distributed Virtual Experiments in Water Quality Management. In: Proceedings of WATERMATEX 2004, Beijing, China, 3-5 November 2004.

Copp, J., Spanjers, H. and Vanrolleghem, P. A., (eds.) (2002). Respirometry in Control of the Activated Sludge Process: Benchmarking Control Strategies, IWA Publishing.

Gernaey, K., Rosen, C., Benedetti, L. and Jeppsson, U. (2005). Phenomenological modeling of wastewater treatment plant influent disturbance scenarios. In: Proceedings of 10th International Conference on Urban Drainage, Copenhaghen (Denmark), 21-26 August 2005.

Gillot, S., De Clercq, B., Defour, D., Simoens, F., Gernaey, K. and Vanrolleghem, P. A. (1999). Optimization of wastewater treatment plant design and operation using simulation and cost analysis. In: Proceedings of 72nd Annual WEF Conference and Exposition, New Orleans, USA, 9-13 October 1999.

Henze, M., Gujer, W., Mino, T. and van Loosdrecht, M. C. M. (2000). Activated sludge models ASM1, ASM2, ASM2d and ASM3. IWA.

Hulsbeek, J. J. W., Kruit, J., Roeleveld, P. J. and van Loosdrecht, M. C. M. (2002). A practical protocol for dynamic modelling of activated sludge systems. Water Science and Technology 45 (6), 127-136.

Langergraber, G., Rieger, L., Winkler, S., Alex, J., Wiese, J., Owerdieck, C., Ahnert, M., Simon, J. and Maurer, M. (2003). A guideline for simulation studies of wastewater treatment plants. In: Proceedings of 9th IWA conference on Design Operation and Economics of large WWTPs, Prague, Czech Republic, 1-4 September 2003.

Melcer, H., Dold, P. L., Jones, R. M., Bye, C. M., Takacs, I., Stensel, H. D., Wilson, A. W., Sun, P. and Bury, S. (2003). Methods for wastewater characterisation in activated sludge modelling, Water Environment Research Foundation, Alexandria, VA, USA - IWA Publishing, London, UK.

Rousseau, D., Verdonck, F., Moerman, O., Carrette, R., Thoeye, C., Meirlaen, J. and Vanrolleghem, P. A. (2001). Development of risk assessment based technique for design/retrofitting of WWTPs. Water Science and Technology 43 (7), 287-294.

Solvi, A.-M., Benedetti, L., Gillé, S., Schlosseler, P., Weidenhaupt, A. and Vanrolleghem, P. A. (2005). Integrated urban catchment modelling for a sewer-treatment-river system in Luxembourg. In: Proceedings of 10th ICUD, Copenhagen, Denmark, 21-26 August 2005.

Vanrolleghem, P. A., Benedetti, L. and Meirlaen, J. (2005). Modelling and real-time control of the integrated urban wastewater system. Environmental Modelling \& Software 20, 427-442.

Vanrolleghem, P. A., Insel, G., Petersen, B., Sin, G., De Pauw, D. J. W., Nopens, I., Weijers, S. and Gernaey, K. (2003). A comprehensive model calibration procedure for activated sludge models. In: Proceedings of WEFTEC 2003: 76th Annual Technical Exhibition \& Conference, Los Angeles, USA, 11-15 October 2003.

Vanrolleghem, P. A., Jeppsson, U., Carstensen, J., Carlsson, B. and Olsson, G. (1996). Integration of wastewater treatment plant design and operation - a systematic approach using cost functions. Water Science and Technology 34 (3-4), 159-171. 